\title{
FOLHAS PARA COLHER FRUTOS: ESCRITA BIOGRÁFICA E AUTOBIOGRÁFICA NOS CONVENTOS FEMININOS PORTUGUESES (SÉCULOS XVII E XVIII)
}

\author{
Ana Cristina Pereira Lage ${ }^{1}$ \\ Terezinha Oliveira ${ }^{2}$
}

\section{RESUMO}

Este artigo analisa a cultura escrita a partir das formas textuais praticadas nos claustros femininos. Serão utilizadas algumas Vidas Exemplares, literatura predominante nos conventos femininos portugueses nos séculos XVII e XVIII. O fortalecimento da individualidade, o surgimento da imprensa e a Reforma Católica propiciaram o avanço da produção de biografias e autobiografias de religiosas que serviam para exemplificar e modelar um estilo de vida conventual considerado ideal aos olhos da Igreja Católica. Eram obras educativas para a normatização religiosa e que atendiam às ordenações masculinas sobre o universo feminino no interior dos claustros.

Palavras-chave: cultura escrita, vidas exemplares, conventos femininos, Portugal, período moderno.

${ }^{1}$ Universidade Federal dos Vales do Jequitinhonha e Mucuri (UFVJM), Diamantina/MG, Brasil.

${ }^{2}$ Universidade Estadual de Maringá (UEM), Maringá/PR, Brasil. 


\title{
HOJAS PARA TOMAR FRUTOS: ESCRITURA BIOGRÁFICA Y AUTOBIOGRÁFICA EN LOS CONVENTOS DE MUJERES EM PORTUGAL (SIGLOS XVII Y XVIII)
}

\section{RESUMEN}

Este artículo analiza la cultura escrita a partir de las formas textuales practicadas en los claustros femeninos. Se utilizarán algunas Vidas Ejemplares, literatura imperante en conventos portugueses en el XVII y XVIII. El fortalecimiento de la individualidad, el surgimiento de la prensa y la Reforma Católica propiciaron el avanzar de la producción de biografías y autobiografías de religiosas que servían para ejemplificar y modelar un estilo de vida conventual considerado ideal a los ojos de la Iglesia Católica. Eran obras educativas para la normatización religiosa y que atendían a las ordenaciones masculinas sobre el universo femenino dentro de los claustros.

Palabras clave: cultura escrita, vidas ejemplares, conventos femeninos, Portugal, período moderno.

\section{LEAVES TO COLLECT FRUITS: BIOGRAPHICAL AND AUTOBIOGRAPHICAL WRITING A IN PORTUGUESE CONVENTS (XVII AND XVIII CENTURIES)}

\begin{abstract}
This article analyses the writing culture from textual modes practiced in female cloisters. Some Exemplary Lives, literature predominant in Portuguese convents in the XVII and XVIII centuries, will be used. The strengthening of individuality, the emergence of the printing press and the Catholic Reformation made possible the advance of biographies and autobiographies by religious women who served to exemplify and to model a conventual lifestyle considered ideal to the eyes of the Catholic Church. These were educational works to the religious normalization and met masculine orders on the feminine universe in the interior of the cloisters.
\end{abstract}

Keywords: writing culture, exemplary lives, convents, Portugal, modern period.

\section{FEUILLES POUR LES PRENDRE DE FRUITS: ECRITURE BIOGRAPHIQUE ET AUTOBIOGRAPHIQUE DANS LES CONVENTS FÉMININES PORTUGAISES (XVIIe ET XVIIIle SIÈCLES)}

\section{RÉSUMÉ}

Cet article analyse la culture écrite à partir des formes textuelles pratiquées dans les cloîtres féminins. Seront utilisés quelques des Vies Exemplaires, la littérature prédominant dans les couvents féminins portugais aux XVIIe et XVIIIe siècles. Le renforcement de l'individualité, l'apparence de la presse et la Réforme Catholique ont conduit à l'avancement de la production de biographies et autobiographies de femmes religieuses qui ont servi d'exemple et de modèle 
d'un style de vie conventuel considéré comme idéal aux yeux de l'Église catholique. Ils étaient des oeuvres éducatives pour la normalisation religieuse et qu'ils ont assisté aux ordinations masculines sur l'univers féminin à l'intérieur des cloîtres

Mots-clés: culture écrite, vies exemplaires, couvents féminines, Portugal, période moderne. 


\section{INTRODUÇÃO}

Porque não se lê neste livro regra, que a vida não possa tomar forma, palavra, que não possa cortar flor, nem folha, que não se não possa colher fruto. 3 (Frei Manoel de Ferreira)

Com estas palavras Frei Manoel de Ferreira, qualificador do Santo Ofício, apresentava o seu parecer do livro Vida da Venerável Madre Isabel do Menino Jesus, autobiografia de uma abadessa do Convento de Santa Clara de Portalegre, cidade do Alentejo português.4 Orientada pelo seu confessor para a escrita autobiográfica5, Isabel (1673-1752) produziu a narrativa de sua vida desde a infância até a aproximação da morte. A autora considerava que tinha limitações na escrita; por esse motivo, pretendia que seu manuscrito permanecesse no 'interior da casa' e circulasse apenas entre as suas companheiras (MENINO JESUS, 1757).

Este livro pode ser categorizado como uma escrita feminina para a divulgação de vidas consideradas 'exemplares', muito comuns no interior dos claustros do período moderno. Comumente, a escrita das autobiografadas era direcionada pelos confessores das religiosas que narravam os caminhos trilhados para o encontro da sua fé no ambiente conventual. Pela análise das vidas exemplares, podemos perceber que a maioria das escritoras não se sentia digna dessa prática e acreditava que tudo o que fazia somente acontecia por

\footnotetext{
3 Este artigo apresenta a transcrição atualizada dos documentos.

4 Segundo Maria Filomena Andrade (2011, p. 107), a fundação do Convento de Santa Clara de Portalegre foi autorizada por D. Fernando, rei de Portugal, em 1370. O rei cedeu o palácio que possuía naquele local para abrigar um mosteiro feminino que seguiria a $2^{\mathrm{a}}$ Regra de Santa Clara. A fundação da instituição partiu da vontade de duas mulheres, Elvira Eanes e Maria Fernandes, que fizeram o pedido ao papa e ao rei com a intenção de se consagrarem à referida Ordem religiosa. A comunidade cresceu "ao longo do período medieval, num movimento que acompanha a revitalização dos núcleos urbanos onde se instalam" (ANDRADE, 2011, p.130). Após as reformas no palácio cedido, o convento passou a funcionar a partir de 1385 e foi extinto conforme a legislação liberal portuguesa de 1834 .

5 Embora a denominação correta utilizada nesse período histórico seja "Vida", neste artigo trabalharemos com as designações de autobiografia e biografia para uma melhor diferenciação, respectivamente, entre a narrativa que era vivida e escrita pela própria freira, daquela que era escrita por sua(s) companheira(s) ou pelo seu confessor (MORUJÃO, 2008).
} 
meio da vontade e pelas mãos divinas. Por outro lado, em suas ações cotidianas eram consideradas distintas das demais religiosas de suas respectivas comunidades e, portanto, suas Vidas eram passíveis de exemplaridade, uma vez que a leitura e a circulação das obras poderiam gerar novos 'frutos', moldados para a produção de religiosas consideradas 'perfeitas' ${ }^{6}$

A 'perfeita religiosa' seria aquela que renunciasse e tivesse um total distanciamento do mundo, além de seguir corretamente as determinações contidas nas Regras e Constituições das suas respectivas ordens. No caso das Irmãs Clarissas, por exemplo, a perfeita religiosa deveria ler e compreender o Ofício Divino em Latim, para então "falar com Deus".7 Assim, o domínio da leitura e o conhecimento de um nível mais aprofundado da língua latina, aliados às demonstrações de ações consideradas exemplares, eram condições necessárias para uma religiosa alcançar a sua perfeição (LAGE, 2014). Mas nem todas as mulheres enclausuradas alcançariam a perfeição, pois a renúncia e o distanciamento do mundo acontecia apenas para poucas - aquelas 'agraciadas' pela vontade divina, passíveis de serem escolhidas e terem as suas vidas narradas para servirem de exemplo às demais religiosas. Para o período histórico que compreende esta pesquisa, 'exemplo' pode ser compreendido como:

\footnotetext{
${ }^{6}$ Sobre a história e a produção de diversas religiosas escritoras dos séculos XVII e XVIII ver: Morujão (1995; 2013); Belo (1993); Carvalho (1997); Hatlerly (1990); Milheiro (2004).

7 Podemos caracterizar como clarissas às mulheres que seguiam Clara de Assis. A denominação Clarissa foi cunhada pelo papa Urbano IV, quando, em 1263, dez anos após a morte de Clara, elaborou uma regra que pretendia ser menos rígida do que a primeira Regra, que foi elaborada pela fundadora e aprovada em 1253. Em linhas gerais, A Regra de Urbano IV foi responsável por estabelecer a obrigatoriedade da clausura e, consequentemente, a entrada de mulheres por meio do pagamento de dotes, posse e acúmulo de bens, contrariando assim os princípios pauperísticos da fundadora. Desde então os conventos urbanistas foram compostos por mulheres de elites locais que poderiam financiar a vida em lugares de reclusão com muita riqueza, o que predominou nos claustros portugueses. No período moderno, observa-se a existência das clarissas que seguiam a Primeira Regra (Descalças); aquelas que seguiam a Segunda Regra (Urbanistas ou Urbanas), que perfaziam a grande maioria do grupo; e aquelas que seguia uma Terceira Regra (Terceiras da Penitência), criada pelo papa Leão X em 1517. (LAGE, 2018). No caso do Convento de Santa Clara de Portalegre, as irmãs seguiam a Segunda Regra.
} 
Coisa, proposta, para ser imitada, ou evitada. Não há coisa mais eficaz que o bom exemplo, nem mais perniciosa que o mal. Nunca fazemos grandes bens, nem grandes males, que não produzam seus semelhantes; imitamos as boas ações por emulação; e seguimos as más por corrupção da nossa natureza (BLUTEAU, 1728, v. 3, p. 380).

O frei Rafhael Bluteau (1638-1734) definia que o exemplo seria algo proposto, passível de imitação se formado por boas ações ou talvez ser evitado, caso levasse à corrupção da natureza humana. A literatura predominante nos claustros femininos portugueses nos séculos XVII e XVIII foi fundamentada em vidas exemplares de algumas religiosas que mostravam um caminho repleto de tentações que poderiam corromper as suas naturezas, mas essas sempre alcançavam um caminho do 'bem' por meio de diversas mortificações, penitências, rezas, martírios e visões sobrenaturais, algo que poderia direcionar o imaginário dos seus leitores para a imitação. A produção das obras exemplares geralmente seguia um caminho que perpassava o direcionamento dos confessores das religiosas, que designavam quais vidas eram dignas de relatos e quais deveriam circular internamente de forma manuscrita ou alcançar outros espaços por meio da impressão. Além disso, a escritora poderia não ter domínio sobre a circulação da sua produção, como foi o caso de Isabel, já que após sua morte e mesmo contra seu desejo expresso no manuscrito, teve a sua Vida publicada por Frei João Evangelista da Cruz e Costa, o qual decidiu que era necessária sua divulgação em outros espaços:

\footnotetext{
Nela acharão todos muito que aprender, e não pouco que admirar, por ser esta uma lição a mais importante, com fatos raras vezes vistos; mas como não seja abreviada a mão de Deus, ainda em nossos tempos, quando a virtude, ou por menos aceita, ou por pouco seguida não aparece, se descobriu uma alma tanto daquele Senhor, que parece transcender as leis ordinárias das mais criaturas (Frei João Evangelista da Cruz e Costa, In: MENINO DE JESUS, 1757, s. n.).
}

As Vidas das religiosas eram obras que educavam por meio das narrativas apresentadas em determinadas trajetórias individuais, que causavam 
admiração e serviam como lição para outras mulheres. Eram produções escritas e lidas nos microcosmos conventuais, geralmente direcionadas e permitidas por vontades masculinas, para disciplinar e ordenar os ambientes claustrais, uma vez que a produção perpassava por diversas instâncias de autorizações, desde o momento da escrita pelas indicações dos confessores, até a aprovação do Tribunal do Santo Ofício para a impressão e publicação das obras, para verificar se havia algo que desqualificaria os dogmas e a fé católicos. ${ }^{8}$

Segundo Roger Chartier (2014, p. 29), os testemunhos de fé preocupavam as autoridades eclesiásticas que tentavam contê-los, impedi-los de circular e até descartá-los. A questão da escrita se tornou o centro das discussões da Reforma Católica e ocorreu até uma sessão específica no Concílio de Trento (1545-1563) para tratar da 'escolha dos Livros', uma vez que o clero considerava que "[...] aumentou muito nestes tempos o número de livros suspeitos e perniciosos nos quais existe e é propagada por todas as partes a má doutrina" (CONCÍLIO DE TRENTO, Sessão XVIII, 1562). Devido à ampliação das traduções e circulação de livros após o surgimento da impressão no século anterior, além das inovações empreendidas pelo movimento reformista protestante, a Igreja Católica sentia-se ameaçada no seu poder de controle do conhecimento a partir da ampliação do poder de leitura e escrita de seus fiéis. A Reforma Protestante foi responsável por ampliar o número de leitores da Bíblia e, consequentemente, instruí-los de uma maneira diferenciada do que era feito pela Igreja Católica até este momento. "Baseada na justificação pela fé, no sacerdócio universal e na única autoridade da Bíblia, a Reforma protestante coloca o fiel em relação direta com Deus, cuja palavra está na Bíblia, que se deve ler e interrogar diariamente" (LEBRUN, 1991, p. 102). Por sua vez, a Igreja

\footnotetext{
8 Em Portugal, o Tribunal do Santo Ofício foi criado pela bula Cum ad nihilmagis, assinada pelo Papa Paulo III em 1536. Por meio do documento, concedia-se ao rei D. João III o poder de nomear ou recusar inquisidores (FEITLER, 2008). Havia uma dualidade de poderes (religioso e político) para o controle da monarquia católica e um dos braços era por meio do controle das publicações de livros, de acordo com a opinião dos qualificadores do Santo Ofício e cujos pareceres constam nas primeiras páginas das obras autorizadas e impressas. É importante salientar que o controle do escrito foi modificado pela Reforma Pombalina quando, em 1769, a fiscalização das obras passou integralmente para as mãos do Estado português, com a criação da Real Mesa Censória.
} 
Católica também realizou a sua própria reforma e, especialmente ampliou os seus quadros educativos por meio da institucionalização de novos modelos escolares (internatos, seminários e colégios), mas também compreendia que era fundamental controlar e censurar a circulação do que era lido para o sucesso desses novos e dos velhos espaços instituídos.

Por meio do controle e aprovação de determinado livro, este tenderia a 'instaurar uma ordem' que tanto poderia ser pela sua decifração, ou quanto à forma como deveria ser compreendido, ou até mesmo seria determinado pela "[...] autoridade que o encomendou ou que o autorizou". Porém, “[...] essa ordem com múltiplas figuras não detém o poder absoluto para anular a liberdade dos leitores [...]" (CHARTIER, 1997, p. 6), pois devemos compreender a existência das diferenças entre as comunidades de leitores. No caso deste artigo, levar em consideração as especificidades das comunidades femininas claustrais. Além disso, a forma como os livros eram lidos e a sua materialidade influenciavam diretamente sua circulação no universo conventual.

Para Roger Chartier, a investigação sobre a produção de um determinado livro leva às indagações acerca de sua autoria, uma vez que "[...] existe supostamente uma relação original e indestrutível entre uma obra e seu autor" (2014, p. 32). Ainda para aquele autor, essa conexão não acontece nem de forma 'universal' e nem sem 'mediação'. Em nossas investigações detectamos, por exemplo, que algumas obras exemplares dos séculos XVII e XVIII não apresentavam autoria e podem ser compreendidas como a escrita de alguma(s) religiosa(s) que conviveu(ram) com a biografada e não se considerava(m) digna(s) de identificação. ${ }^{9}$ Com relação às mediações da escrita, observamos que, na maioria das vezes, elas passavam pelas ordens dos confessores e algumas apresentavam a indicação da pouca vontade das autoras para escrever, como é possível identificar no manuscrito autobiográfico de Sóror Mariana da Purificação, do Convento de Santa Clara de Évora:

\footnotetext{
9 Um exemplo seria a Breve relação da vida e morte prodigiosa da Madre Maria Joanna, biografada por suas companheiras do Convento de Louriçal, sem indicação de autoria e publicada no mesmo ano de sua morte (1754).
} 


\begin{abstract}
Obrigada de mandado e obediência de V. Padre me sacrifico a escrever aqui os favores e mercês que Deus N. Sr. por sua infinita misericórdia me fez sem eu lho merecer, o que não poderá deixar de ser com muitas lagrimas sendo e conhecendo o que sou suposto de mim mas tenho o verdadeiro conhecimento que Deus o que bem se deixa ver na muita repugnância que hei tido e tenho em obedecer aqui a V. Padre (PURIFICAÇÃO, 1694, s. n.).
\end{abstract}

A narrativa demonstra certo sofrimento e sacrifício da autora para a prática da escrita, como também o poder de seu confessor em direcioná-la para esta atividade. Além disso, a narrativa é construída por meio de um conhecimento que foi apresentado pela vontade divina. Segundo Maria del Mar Graña Cid (2001, p. 423), este sofrimento pela escrita fazia parte da experiência mística de muitas mulheres, uma vez que evidenciava as suas dificuldades de usar a linguagem e o sistema de significados que dariam voz pública ao que desejavam comunicar. Assim, ainda que contra a sua vontade, Mariana da Purificação se propôs à tarefa e - assim como Isabel do Menino Jesus produziu sua autobiografia.

Este artigo objetiva analisar algumas biografias e autobiografias produzidas no período Moderno por mulheres reclusas em conventos portugueses. As obras demonstram uma estrutura com muitas semelhanças, porém com marcas das particularidades dos locais e das personalidades dos autores ou autoras. A proposta insere-se no campo historiográfico e metodológico da História Cultural, uma vez que dialoga com o campo temático da História da Educação e as especificidades da Cultura Escrita, por meio da análise de obras caracterizadas como biográficas e autobiográficas. Após o levantamento dos documentos em arquivos portugueses ${ }^{10}$, realizamos a seleção e leitura das obras mais significativas para utilizarmos neste trabalho. As biografias e autobiografias são aqui consideradas enquanto fontes e

\footnotetext{
${ }^{10}$ Esta pesquisa é fruto de um projeto de pós-doutorado desenvolvido na Faculdade de Educação da Universidade Estadual de Maringá no ano de 2017 e com o apoio da Capes. Durante os meses de abril a junho desenvolvemos o levantamento de fontes em Portugal, nos seguintes espaços: Arquivo Nacional da Torre do Tombo, a Biblioteca Nacional de Portugal, a Biblioteca Nacional da Ajuda e a Biblioteca Municipal de Évora.
} 
consideramos que as reflexões estabelecidas neste artigo, são importantes para o fortalecimento das pesquisas acerca do campo da história da cultura escrita feminina, uma vez que as mulheres que residiam nos ambientes claustrais eram grandes produtoras de escrita (manuscrita ou impressa).

\section{CULTURA ESCRITA E SUAS PRÁTICAS}

Neste artigo dialogamos com uma definição da cultura escrita como sendo o lugar "[...] que o escrito ocupa em/para determinado grupo social, comunidade ou sociedade" (GALVÃO, 2010, p. 218). Torna-se importante analisar os caminhos percorridos para a divulgação do escrito quando se investigam grupos de mulheres que seguiam determinadas regras religiosas e que buscavam um estilo de vida específico, o que possibilita a compreensão das práticas que usavam em relação à escrita. Salientamos, ainda, as especificidades de análise da cultura escrita nas suas práticas (escrita e/ou leitura), em ambientes femininos e religiosos, em períodos históricos e espaços distintos (GONZALES DE LA PEÑA, 2005).

O historiador da cultura escrita deve direcionar a sua investigação em três direções: os discursos, as representações e as práticas (GOMEZ, 2003). O discurso é uma doutrina ou ideologia que trata de regulamentar e sistematizar o funcionamento de uma sociedade; as fontes para compreendê-lo consistiriam em todos os textos socialmente autorizados por meio dos quais se estabelece e se propaga uma determinada concepção da escrita e da leitura. Por sua vez, as representações envolvem distintos modelos de imagens que cada sociedade constrói a propósito dos temas e objetos da cultura escrita. Devido aos limites de um artigo, delimitaremos as nossas reflexões às práticas, embora sempre tangenciando os discursos e as representações, uma vez que estão sempre imbrincados nos processos de escrita.

As práticas são aqui compreendidas como 'maneiras de fazer' cotidianas 
dos sujeitos históricos, relacionadas social e culturalmente na construção de seus espaços, suas posições e suas identidades. Elas implicam o estabelecimento de estratégias que se distanciam quando pensamos nas diferenças entre as práticas de leitura e escrita em determinados espaços e com relação a determinados grupos sociais (CERTEAU, 1996). Ler e escrever são práticas distintas e isso se torna evidente quando analisamos os conventos femininos do período moderno, uma vez que nem todas as religiosas liam e um número ainda menor escrevia, propiciando níveis distintos de aprendizado. Muitas vezes, as práticas de escrita eou leitura dependiam de um aprendizado adquirido antes do ingresso na vida religiosa, pois apenas algumas regras autorizavam este ensino nos momentos de noviciado que antecediam à profissão. No noviciado, o ensino estava mais voltado para o fortalecimento de uma moral e um jeito de ser religiosa em uma respectiva ordem ou congregação. No caso das irmãs clarissas, as Constituições Gerais (1693) informam que o aprendizado da leitura deveria ocorrer antes do ingresso, uma vez que, no Convento, “[...] as que não sabem ler, não tratem de aprendê-lo" (1693, p. 15). Essa proibição devia-se ao fato de que o domínio da leitura era um delimitador das distintas atividades no interior dos claustros clarianos, onde havia dois tipos de religiosas: as Irmãs de Coro, que poderiam ler o Breviário nos momentos de Ofício Divino" ${ }^{11}$; as Irmãs Conversas, aquelas que não dominavam a leitura e apenas rezavam algumas orações. Ter o domínio da leitura refletia, também, nos hábitos portados pelas religiosas clarissas, uma vez que as irmãs de Coro usavam em suas cabeças um véu preto e as Conversas um véu branco. No entanto, salientamos que, mesmo não tendo o domínio da leitura, as irmãs Conversas clarissas participavam de um determinado aprendizado no Ofício Divino quando ouviam a leitura em voz alta das Irmãs de Coro (LAGE, 2014).

As distinções apresentadas entre as irmãs de Coro e Conversas não eram prerrogativa das clarissas do período moderno, pois se verifica que, em

\footnotetext{
${ }^{11}$ Os breviários eram livros que continham orações em latim que seriam lidas em momentos determinados e que constituíam o Ofício Divino. Geralmente, a leitura dos breviários era realizada pelas irmãs no Coro da igreja do Convento.
} 
várias temporalidades e com finalidades distintas, outras ordens e congregações femininas receberam noviças de distintas origens, direcionadas para funções claustrais também distintas (HUFTON, 1991). Em geral, cabia às ingressantes mais pobres o cuidado com os trabalhos manuais e a limpeza dos espaços conventuais. Ainda no século XX, em algumas ordens e congregações, o aprendizado de leitura eou escrita era totalmente vedado ou apresentava níveis distintos para as irmãs mais pobres, uma vez que este se tornava um diferencial para as mulheres mais ricas e que portavam dotes mais vantajosos para a Igreja Católica (LAGE, 2016).

Compreendemos que a leitura é uma prática "[...] encarnada em gestos, espaços, hábitos [...]” e o método empregado pressupõe contrastes nas suas competências, entre as normas e convenções que definem as comunidades de leitores e, finalmente, entre as expectativas e os interesses que os "[...] vários grupos de leitores investem na prática de ler" (CHARTIER, 1997, p. 15). Pensar os grupos de leitores propicia a objetivação das identidades femininas em sua estreita relação com a cultura escrita nos ambientes conventuais, uma vez que "as leituras das religiosas dependiam de fatores que vão desde as existências bibliográficas na casa até à possibilidade - que pode ser oportunidade - de aquisição dos textos" (CARVALHO, 1997, p. 16). Somam-se a isso as implicações das diferenças sociais presentes nos conventos entre as mulheres leitoras e não leitoras, aquelas que ouviam ler.

As diferenças entre ler e ouvir ler podem ser verificadas por meio da análise das cartas espirituais encaminhadas para diversas religiosas pelo frade franciscano Antônio das Chagas (1631-1682), o qual aconselhava: "Leia poucos livros que os muitos confundem; se pegue a um, e especialmente o escolha, seja qual for; e que ouvindo as virtudes e vidas dos Santos as imite quanto puder" (Antônio das Chagas apud CARVALHO, 1997, p. 23). Para o franciscano, a leitura e o ouvir ler, atividades distintas, tinha que ser de poucas obras, desde que essas fossem de qualidade e com possibilidades de imitação. A ideia seria ler, repetidamente, uma mesma obra com o propósito de que o conteúdo fosse 
internalizado.

Embora a Igreja Católica almejasse um modelo ideal de leitora nos séculos XVII e XVIII, é necessário pensar que este geralmente não correspondia às leitoras reais nos claustros, pois o modo de assimilação e decodificação do texto era muito heterogêneo entre as religiosas. A leitura poderia acontecer de forma distinta nos claustros: coletivamente e em voz alta ou individualmente e em silêncio. As Constituições Gerais (1693) informam que a leitura de obras 'autorizadas' faria parte do cotidiano das irmãs Clarissas leitoras e a prática poderia ser realizada em comunidade ou individualmente. A leitura em comum aconteceria nos momentos de celebração do Ofício Divino, durante as refeições ou em atividades manuais já que, nestes dois últimos momentos, sempre existiria uma encarregada em ler para não deixar o 'pensamento livre' daquelas que comiam ou trabalhavam ${ }^{12}$. Além disso, cada freira leitora teria uma hora de oração mental e silenciosa por dia: “[...] E antes da Oração se leia um livro espiritual, que administre matéria para a Oração, e contemplação" (CONSTITUIÇÕES GERAES, 1693, p. 84). Esses livros poderiam pertencer à comunidade ou cada religiosa poderia ter as suas próprias obras 'edificantes' e guardá-las em suas celas.

A entrada de livros considerados 'perniciosos' deveria ser combatida. O padre francês Michel-Ange Marin (1697-1767), autor do livro A perfeita religiosa (1750), que teve ampla circulação após sua tradução e publicação em Portugal (1789), assim definia a 'desordem' causada pela entrada de 'maus livros' nos claustros:

E que pecado não é introduzirem maus livros em um Mosteiro, quer eles ataquem a Fé, quer possam alterar a pureza dos costumes? Ah, quanto os que se atrevem a cometer um tão funesto atentado hão de

12 Indubitavelmente, seguem os princípios indicados por Bento de Núrsia quando do estabelecimento das Regras Monásticas, no capítulo IV, em que se definem os instrumentos de boas obras, especialmente a de n. 55 - 'Ouvir de boa vontade as santas leituras'. Assim, se observa a conservação de uma tradição de hábitos de longuíssima duração (REGRA de São Bento, c. 530, p. 10). 
ter que dar uma terrível conta a Jesus Cristo do perigoso laço que armam as suas Sagradas Esposas. [...]

Oh Virgens Esposas de Jesus Cristo, rogo-vos em nome do que é esposo de vossas Almas, estejais soberanamente vigilantes por este lado. Rejeitai horrorosamente esses venenos mortais, que mãos homicidas se atrevem a oferecer-vos em taças de ouro. Não chegueis jamais com vossa curiosidade, nem sequer a abrir tais livros. Não façais escolha, senão dos que podem instruir-vos de vossas obrigações; demonstrai-vos à prática deles, e animai-vos a serdes-lhes fiéis. Se lerdes outros, abrireis a porta do inimigo de vossas Almas; advertindo, que das destruições que eles nelas fizer, só de vós mesmas vos devereis queixar (MARIN, 1789, p. 42-43).

O padre francês indicava que os livros considerados 'maus' não poderiam adentrar nos claustros e, caso isso ocorresse, caberia às religiosas rejeitarem sua leitura. Somente as obras 'instrutivas' seriam consideradas 'boas' para a leitura conventual, ou seja, aquelas que modelassem e organizassem os claustros de acordo com a vontade da Igreja Católica. O livro poderia ser visto então como um instrumento de controle educativo por direcionar a imitação de um modelo ideal por meio da leitura, mas, por outro lado, é necessário considerar que ele poderia fortalecer a identidade das mulheres como 'agentes do discurso', no momento em que estas se tornavam produtoras das obras que circulavam nos microcosmos conventuais.

A escrita é um instrumento gráfico que se apresenta como um sistema comunicativo distinto da oralidade, com determinadas regras e funções. Ela se torna uma palavra pública, autorizada, geralmente reservada aos homens e com limitado acesso às mulheres (GRAÑA CID, 2001). Para compreendermos essa diferenciação na aquisição da escrita com relação ao gênero é necessário delimitar os distintos espaços de atuação de homens e mulheres no catolicismo, uma vez que:

A escrita elaborada mais de acordo com modos de pensamento e expressão característicos de culturas letradas estaria vinculada aos primeiros, aos quais a Igreja facultava uma educação mais extensiva e o direito de explorar e enunciar questões teológicas e legais. Escritas 
mais "orais" seriam predominantes na esfera monástica feminina (BELLINI, 2010, p. 232. Destaque da autora).

As escritas consideradas 'mais orais' seriam aquelas produzidas no interior de culturas marcadas pela oralidade, tendo como referência central acontecimentos próximos e sem muito distanciamento dos objetos narrados (BELLINI, 2010). Assim, quando investigamos as obras exemplares produzidas pelas irmãs nos conventos portugueses, encontramos narrativas de um tempo presente e cotidiano das religiosas, com uma escrita direta e sem muita preocupação com a sua elaboração e refinamento. Frei Jerônimo de Belém assim expressava a sua opinião sobre o seu estilo de escrita de Isabel do Menino Jesus:

\footnotetext{
Este juízo sobre a doutrina corrente dos santos, e servos de Deus, formo eu da matéria deste livro, e do espírito de sua Autora; porque, sendo certo, que não teve mais estudo, que o da santa Oração, em que gastava muitas horas, e de ordinário, noites inteiras, com o exercício de outras virtudes, bem se insere, que só nesta escola podia aproveitar, para escrever uma matéria toda mística, fundada nas regras; e princípios de uma ciência, verdadeiramente dos santos (MENINO JESUS, 1757, s. n.).
}

Na opinião do religioso, a religiosa não teve muitos estudos e, por isso, sua escrita fundamentava-se principalmente nas suas orações, conhecimentos de regras e leituras de vidas dos santos, com um estilo de escrita pouco rebuscado. Porém, por meio da análise da autobiografia de Isabel é possível detectar que ela teve contato com outras obras, especialmente com uma literatura considerada 'profana' e distante da religião. Isabel do Menino Jesus aprendeu a ler e escrever aos 13 anos, quando ainda estava na casa de seus pais, causando estranheza aos seus familiares que uma menina adentrasse no universo da cultura escrita: "[...] porque as mulheres corriam muitos perigos, e não se podiam fiar delas; e sendo meu Pai um homem sumamente nisto acautelado, respondeu, que seria para ele uma grande honra, ler, e escrever sua 
filha” (MENINO JESUS, 1757, s. n.). O aprendizado de Isabel propiciou o desenvolvimento da sua prática de leitura e escrita, o que teria contribuído na tarefa de educar sete sobrinhos órfãos. A vontade de se tornar religiosa somente apareceu aos 25 anos, após tomar emprestado um livro de parábolas de um cunhado:

\begin{abstract}
Levei comigo o livro, e fui descobrindo, o que nele se continha, e sempre com esperanças de que era livro profano; porque o mundo me tinha cega, que não acabava de entender a verdade. Aqui, como fica dito, apareceu o Sol com raios de luz; porque Deus me infundiu luz superior, que logo desterrou as trevas da minha ignorância: conheci o erro em que vivia, e me levava ao inferno. Foi tão veemente o conhecimento, que Deus me deu desta verdade, que sem mais dilação, tomei logo o livro por mestre; porque não tinha nunca noticia, de que houvesse Padre, que governasse almas, nem houvesse exercício de Oração mental; porque estes bens espirituais estavam nestes tempos muito ocultos (MENINO JESUS, 1757, s. n.).
\end{abstract}

Sua conversão ocorreu por meio da leitura de um determinado livro, importante o suficiente para 'iluminar' o conhecimento de Isabel e primordial para engatilhar os seus anseios de tornar-se freira. Sua entrada para o Convento de Santa Clara de Portalegre foi tardia, uma vez que somente aos 35 anos teve a aprovação de seu pai. Neste momento, considerou que a comunidade claustral na qual era inserida apresentava certo atraso em suas orações em relação ao conhecimento que ela já possuía, o que causou certos problemas em sua adaptação local. Porém, se aos olhos da comunidade clariana de Portalegre, Isabel se distinguia em seu conhecimento por meio das leituras adquiridas, como autora de uma obra exemplar e mística, ela demonstrou insegurança e sua escrita apresentou 'limitações'.

Pois agora na observância da obediência aprendi a ser discípula, que na variedade de tantos pensamentos, como eu tinha, por estar metida na terra da natureza, não me podia dar luz, para escrever mística; pois não tinha capacidade de fazer forma de livro, por me faltar ciência, e pouco espírito, e sem nenhum uso de retórica, e só muitas ignorâncias, 
que poderiam ficar manchadas de erros; mas por esta mesma causa, persuado aos senhores Doutores místicos vejam estes papéis, que para Autores desta obra os busca a minha obediência, pedindo a todos me queiram ensinar o que eu não sei (MENINO JESUS, 1757, s. n.).

Sua escrita só foi possível quando se distanciou do mundo 'profano', uma vez que ele tinha 'muitas ignorâncias', mas, mesmo assim, percebia que necessitava de correções e de ensinamentos dos 'Doutores' para o desenvolvimento de sua obra. Isabel fala das suas limitações e da necessidade de aprender o que desconhecia. Parece que a 'luz' que ela descobriu ao ler o livro de parábolas não era a mesma no momento de sua escrita autobiográfica, o que revelaria os desníveis apresentados em suas práticas de leitura e escrita. Mesmo que sua vida fosse considerada digna de um relato autobiográfico, ela se considerava limitada por fazê-lo. Essa limitação é evidenciada nos diversos pareceres dos qualificadores do Santo Ofício, apresentados ao início das vidas exemplares que eram impressas. Eram mulheres que não se consideravam dignas de escrever, mas que obtinham a permissão para executar essa prática pelas mãos de homens que se consideravam mais sábios e que precisavam da circulação de uma escrita exemplar que propiciassem leituras para educar e ordenar os ambientes claustrais. Porém, essa escrita feminina sempre era tratada em suas limitações com relação às capacidades masculinas de adentrar no universo da cultura escrita.

\section{A ESCRITA E A LEITURA FEMININAS CONVENTUAIS}

Como espaço de criação literária, o convento assume um relevo considerável a partir do século XVII, pois é nesse momento que "[...] emerge, em movimento de irreversíveis contornos (sobretudo pela publicação que atingiu através dos prelos), a regularidade e diversificação da escrita feminina no âmbito dos parâmetros monásticos" (MORUJÃO, 2013, p. 83). A realidade 
portuguesa de expansão da escrita, nos claustros femininos, tardia com relação a outros espaços europeus, pode ser definida como uma 'estratégia pedagógica barroca'.

A cultura barroca (meados do século XVII e primeira metade do XVIII) era caracterizada por uma sociedade em crise e mutação, "[...] pautada por guerras de religião e dominada por um espírito místico e de paixão" (MILHEIRO, 2004, p. 26). A literatura dessa época apresenta três princípios: entretenimento, didatismo e intenção de transformação do leitor. As obras exemplares eram didáticas e educavam as religiosas em seus processos de transformação e adequação ao instituído pela religião.

\begin{abstract}
De facto, não parece difícil admitir-se que a aceitação de que mãos femininas, através da escrita, divulgassem preceitos morais, normas espirituais ou padrões de conduta tenha constituído um surpreendente e eficaz processo de brandir o novo, ao serviço da manutenção da ordem dominante. Essa novidade residia não só na origem feminina da escrita, mas também no registo mais afectivo que a escrita de religiosas arrastava consigo, mecanismos que, conjugados, reforçavam a capacidade persuasiva dos textos que pretendiam modeladores (MORUJÃO, 2013, p. 84).
\end{abstract}

Destacamos, também, que a maioria das escritoras conventuais fazia parte de uma elite econômica e social que adentrou nos claustros e que criou uma 'rede de trocas' de influências nos meios eclesiásticos, políticos e editoriais (BELLINI, 2010). Eram leitoras e, em menor número, escritoras. As mulheres que dominavam as duas práticas, nos claustros, eram distintas daquelas que só liam e, mais distintas ainda daquelas que não sabiam ler e escrever.

Para Leila Mezan Algranti (2004), é possível encontrar dois modelos de escritoras conventuais: as 'escribas', que produziam manuscritos, e as 'literatas', aquelas que conseguiam publicar as suas obras. Nos claustros, existiam três exemplos de escrita: uma doméstica ou institucional, voltada para a administração da casa (livros de contas, registros de entradas, óbitos ou profissões de religiosas); uma de foro íntimo ou privado (cartas ou escritos de 
consciência aos confessores) e, por fim, as autobiografias ou biografias de companheiras de clausura. O período moderno foi responsável pelo fortalecimento da escrita biográfica, uma vez que "a vida de renúncia e mortificação dos místicos medievais passa a ser apresentada não como obra de personalidades e vocações excepcionais, mas como modelo acessível para o comum dos mortais" (BELO, 1993, p. 34). É importante salientar que a escrita das vidas de religiosas foi um gênero literário predominante, específico na modernidade. ${ }^{13}$ Porém, Isabel Morujão (2013) nos indica que o universo literário claustral feminino português foi bastante complexo. ${ }^{14}$

Em face da existência de diversos estilos, faz-se necessário analisar as diferenças quantitativas na produção literária das enclausuradas. Nos diversos arquivos portugueses é possível encontrar desde pequenas obras manuscritas que nunca foram impressas e que provavelmente só circularam dentro de um único claustro, até os livros impressos escritos por religiosas que produziram uma vasta produção literária, com diversas publicações e popularidade. Dentre todas as escritoras, destaca-se Sóror Maria do Céu (1658-1753), religiosa clarissa do Real Convento de Nossa Senhora da Esperança de Lisboa, que produziu uma literatura de natureza diversa, como vidas de santas e religiosas exemplares, comédias e peças teatrais (FARIA, 1994). Nos primeiros anos de sua produção literária, escreveu sob o pseudônimo de Marina Clemência. A prática de se usar um codinome era comum na época e poderia demonstrar a intenção de manterse no anonimato ou a possibilidade de escrever sobre temas proibidos aos olhos da Igreja Católica (BELO, 1993). Todavia, segundo Paulo (2005, p. 16), parece

13 Para além das obras específicas de Vidas exemplares que são aqui analisadas, Moreno Laborda Pacheco aponta a existência de pequenos relatos das mulheres destacadas nas comunidades claustrais, ao analisar em sua tese de doutorado os livros de fundação de diversos conventos portugueses. Constata que a inserção de pequenas vidas exemplares em suas fontes pode ser considerada enquanto "tendência editorial, corrente à época, de produzir e publicar relatos biográficos de homens e mulheres crescidos na virtude" (2013, p. 221).

14 "O poema épico, a crônica, a biografia, a autobiografia, o relato hagiográfico, a novela, as comédias e autos, as meditações, as novenas, os métodos de oração, as Regras, o sermão, o comentário místico, as paráfrases de salmos, os colóquios, as cartas, a poesia encomiástica, a écloga, o soneto, a elegia, a epístola, o vilancete, o vilancico, o romance, a redondilha e a medida nova, etc. constituem provas indiscutíveis da complexidade dessa literatura e da riqueza de suas matrizes" (MORUJÃO, 2013, p. 129). 
que Maria do Céu queria o anonimato, na medida em que o conjunto dos seus escritos apresenta uma "[...] assimilação da vertente moral [...]" e da sua erudição "[...] resulta uma hibridização que é uma das principais características do barroco literário" (PAULO, 2005, p. 16). A religiosa entendia sua atividade literária como uma maneira de louvar a Deus, sempre com o propósito de ensinar e evangelizar, como propunha no direcionamento ao leitor na obra intitulada A Fênix Aparecida na vida, morte, sepultura e milagres de Santa Catarina (1715):

Com que tu, ó devoto leitor, não tens de duvidar nas circunstancias que aqui narro da peregrinação e Igreja de Santa Catharina; tens, sim, muito que imitar em sua vida, nela aprenderás todas as virtudes: em seu valor, a ser nos trabalhos forte: em seu zelo, a ser na verdade destemido: em sua pureza, a ser em tuas obras imaculado: em seu fervor, a ser em tua Fé ardente: em sua piedade, a ser em tuas dadivas misericordioso: e assim veras por eternidade no Céu, a que servistes por dias na terra (Marina Clemência apud BELO, 1993, p. 44).

A preocupação da autora em narrar a vida de Santa Catarina de Alexandria (século VI) estava em apresentar o seu fervor e exemplo para os seus leitores. Observamos que as narrativas hagiográficas (relatos de vidas de santos) eram predominantes no período medieval e o gênero que se destacava no século XVIII eram as biografias ou autobiografias de religiosas exemplares. A hagiografia era "[...] composta com vista à promoção da santidade de um herói, o santo, pelo relato das acções miraculosas da sua vita" (VIEIRA, 1996, p. 17).

As Vidas exemplares das religiosas se distanciam das hagiografias medievais, uma vez que estabelecem uma relação diferenciada com a divindade: “[...] mais próxima e menos temida, este é o objeto de um amor devocional por parte de um sujeito activo e consciente da sua individualidade" (BELO, 1993, p. 35). Com efeito, é preciso distinguir as hagiografias das vidas exemplares, uma vez que as primeiras seriam responsáveis por promover a santidade de um herói por meio de suas ações miraculosas, constituindo-se como uma história catequética e um espelho para orientar os fiéis sobre um universo excepcional e 
maravilhoso. A biografia devota, por seu turno, seria responsável por colher "[...] da biografia sagrada o objetivo de glorificação de Deus pela exemplaridade do protagonista e edificação do destinatário, pela imitação das suas virtudes" (VIEIRA, 1996, p. 19). A valorização das biografias e autobiografias, nesta época, estaria relacionada à ampliação do público leitor e escritor por intermédio das mudanças educativas e a publicação e circulação de livros impressos.

Quando analisamos as Vidas das Religiosas dos séculos XVII e XVIII, podemos traçar uma regularidade nas narrativas, como a falta de discussão acerca das personalidades dos indivíduos e de preocupação com a cronologia. Ligia Bellini (2010) aponta três partes que se repetem nas Vidas das religiosas: a narrativa sobre o período que antecede a entrada no mosteiro e concentra-se no momento de conversão; a vida no convento e virtudes das irmãs; por fim, uma morte detalhada. Esse modelo circulava nos ambientes claustrais e o que diferenciava uma obra de outra eram as particularidades individuais de cada uma das biografadas.

\section{UMA POSSÍVEL ESCRITORA: SÓROR MARIANA DO ROSÁRIO}

Nesta seção, refletiremos sobre uma Vida exemplar da qual encontramos, no mínimo, três versões: uma autobiografia desaparecida; uma biografia/autobiografia manuscrita realizada por uma companheira de claustro (ESPÍRITO SANTO, 1649) e a impressão de uma biografia redigida por um religioso (ALMADA, 1694). Trabalharemos com a hipótese de Sóror Mariana do Rosário (1615-1649), religiosa franciscana do Convento de Salvador de Évora ter escrito a sua biografia, uma vez que não encontramos os manuscritos nos arquivos portugueses, mas somente resquícios de papéis que o tempo preservou e que dão mostras da existência dela. Estabelecidas essas condições, teremos duas possibilidades de narrativas para pensar esta história. 
A primeira está contida em papéis avulsos e manuscritos deixados por uma religiosa do referido convento, Sóror Helena do Espírito Santo, intitulada Vida e morte de Soror Marianna do Rosário Religiosa professa filha da Me. Sta Clara que viveo e morreo com opinião de Sancta em o Religioso Convento de Salvador da cidade de Évora (1649). Logo no início, a religiosa deixa claro que apenas fez uma cópia dos escritos de Sóror Mariana do Rosário:

\begin{abstract}
Estes papéis são um traslado do que escreveu soror Mariana do Rosário, por mandado de seu confessor para ver se haveria nisto algumas dúvidas ou enganos. [...] nem é tenção em nada em condenar os decretos de sua santidade em escrever revelações e milagres nem aprová-los, nem que se lhe dê mais crédito, que um dito simples, que se guardar se perdessem os originais, ou tivessem algum perigo se conservar em neste traslado (ESPÍRITO SANTO, 1649, p. 1).
\end{abstract}

A intencionalidade da cópia dos escritos era de preservar a história de Mariana do Rosário, uma espécie de precaução diante de uma possível perda dos originais, fato que efetivamente ocorreu ao longo do tempo. Nas páginas finais do manuscrito, o documento perde o caráter de 'cópia da autobiografia' e torna-se uma biografia escrita por Sóror Helena do Espírito Santo, uma vez que esta apresenta sua versão do final da vida da sua companheira de claustro:

O que até aqui está escrito é o que achei de sua própria mão se não sinal onde começa, o que vai ainda há não tem que havesse que é deste último ano de 1649. [...] algumas coisas me disse nessa última enfermidade, e me pediu os apontasse com um memorial, para que se a doença lhe desse lugar o fazer por sua mão e tudo me disse com muita brevidade por lhe dar pena o falar (ESPÍRITO SANTO, 1649, p. 84).

A escrita de Sóror Mariana foi realizada, provavelmente, a partir de 1646, nos quatro anos finais de sua vida e parece-nos que, no último ano, contou com o auxílio de Sóror Helena para finalizar a sua narrativa (ESPÍRITO SANTO, 1649). A análise do documento manuscrito de noventa páginas apresenta a 
mesma grafia, mas um estilo diferenciado nas últimas seis, já que nesta parte a autora escreve na terceira pessoa e faz apenas alguns apontamentos factuais acerca do final da vida da religiosa. Em contraponto, as oitenta e três páginas iniciais são escritas na primeira pessoa e apresentam minuciosamente detalhes das vivências místicas de Mariana do Rosário.

A segunda narrativa trata-se de uma obra impressa (346 páginas) e intitulada Desposorios do Espirito, celebrados entre o divino Amate, e sua amada Esposa a venerável Madre Soror Marianna do Rosario, religiosa do veo branco no Convento do Salvador da cidade de Évora (1694), organizado pelo frei agostiniano Antônio de Almada. No início, na sessão 'A quem ler', em seu papel de historiador dos Seiscentos, Frei Antônio de Almada apresenta como foi o seu processo de investigação e escrita do livro:

Da vida desta serva de Deus se acham em Évora alguns livros manuscritos, pelos quais me pareceu não seria bem reger esta história, não só porque ignorando-se o autor deles, fica suspeitoso o crédito do que neles se refere, mas também porque notei no seu estilo algumas impropriedades, que nasceriam talvez, ou da pouca fidelidade em quem os trasladou, ou de falta de estudo em quem primeiro os escreveu.

E como das histórias a alma é a verdade, eu para melhor descobrir esta, a fui buscar ao Convento do Salvador, aonde a venerável Soror Mariana viveu. Ali achei os mesmos originais que ela escreveu por mandado de seu Confessor, e um processo jurídico de testemunhas, que depois de seu falecimento se perguntaram, das quais notícias colhi o que aqui escrevo (ALMADA, 1694, s. n.).

O autor nos informa que, no momento de sua escrita, cerca de cinquenta anos após a morte de Mariana, já existiam algumas versões da sua história. Porém, para tecer a sua obra, consultou o original autobiográfico, como também um processo ocorrido após a sua morte e que tratava de julgar a fé da religiosa, pois não confiava nos demais documentos. Almada informa, ainda, que procurou seguir o mesmo estilo 'singelo' de Mariana em sua escrita e apenas modificou a repartição dos assuntos, incluindo capítulos e parágrafos, para uma 
melhor compreensão do percurso da vida exemplar. De forma diferente, no manuscrito de Helena do Espírito Santo (1649), a história tinha a sua divisão pela indicação de dias santos. A intenção, na publicação da história, perpassava a ideia de ampliar o número de pessoas que pudessem conhecer e seguir o exemplo de Mariana do Rosário: “[...] eu busco nesse livro a glória de Deus, e não a minha opinião, satisfeito ficará o meu trabalho, se vir que dele resulta conhecerem-se as maravilhas do Senhor e imitarem-se as virtudes de sua Serva" (ALMADA, 1694, s. n.).

Mas afinal, quem foi Mariana do Rosário e por que sua vida recebeu tanta atenção em seu Convento e fora deste? Pelas aproximações de dados constantes no manuscrito de Sóror Helena do Espírito Santo (1649) e no impresso de Frei Antônio de Almada (1694), é possível traçar sua trajetória desde o nascimento até sua morte. Filha de pais pobres, desde pequena desejava entrar no Convento de Salvador de Évora. No entanto, o pai só tinha dinheiro para meio dote, o que possibilitou sua entrada como uma freira conversa de véu branco. A condição econômica de Sóror é outro fator que propicia o nosso questionamento sobre a capacidade de escrita e a produção de sua autobiografia, uma vez que era vetada às irmãs de véu branco a prática da leitura. Como a prática de escrita feminina era ainda mais restrita do que a de leitura, como foi possível para Mariana do Rosário escrever sua própria história? O aprendizado da escrita foi diferenciado:

Começou Sóror Mariana depois de mulher crescida a aprender uma arte, a cujo estudo se costumam dar as criaturas de pouca idade, e foi caso maravilhoso de todos, que dentro do tempo de um mês soube escrever. Parece quis Deus assim mostrar era ordenado isto com especial Providência sua, pois de outra fonte não era crível, que em tão breve tempo se pudesse alcançar o que para se conseguir depende ordinariamente de mais dilatados estudos, e diligências (ALMADA, 1694, p. 289).

Após ser orientada por seu confessor sobre a necessidade de escrever sobre sua vida exemplar e considerando-se incapacitada para tal 
empreendimento, Sóror teria se dedicado a aprender os rudimentos da escrita, no interior do claustro. Por sua vez, Antônio de Almada considerava que a escrita de Mariana não era elaborada e seria necessário “[...] ver a grande humildade com que fala, e singeleza com que se explica, sem afetar palavras, nem conceitos, usando de um estilo chão, uma frase sem estudo" (ALMADA, 1694, p. 299).

Longe de opinarmos acerca da capacidade e aquisição da escrita por parte de uma religiosa conversa de véu branco, preocupamo-nos em considerar como as narrativas intrigam ao leitor atual. Ao analisarmos a Vida de Sóror Mariana do Rosário disposta tanto por Sóror Helena do Espírito Santo (1649) quanto por Frei Antônio de Almada (1694), compreendemos como uma religiosa que trabalhou a maior parte do tempo na enfermaria do Convento e deveria ter uma relação de subserviência em relação às religiosas de véu preto, teve a capacidade de se destacar em suas atividades e opiniões entre suas companheiras. Provavelmente, as diversas audições e visões, contatos sobrenaturais com Maria, Jesus Cristo, o Espírito Santo e o demônio apresentados nas narrativas demonstram uma valorização da religiosa que, em nome da 'vontade divina', aconselhava, repreendia e até determinava como seria a condução do convento.

Em alguns momentos, as narrativas esbarram em questões que poderiam gerar compreensões controversas aos dogmas da Igreja Católica. Salientamos a passagem na qual, após uma 'conversa com Jesus Cristo', Mariana do Rosário declarou que todas as suas companheiras seriam salvas no momento do Juízo Final (ALMADA, 1694, p. 306). Um problema estava posto então no microcosmo conventual, uma vez que a promessa da salvação era $o$ grande eixo condutor da Igreja Católica para gerar pessoas mais educadas e conformadas aos seus preceitos. E como seria possível propiciar uma formação de religiosas que já tinham assegurada a salvação? Como Sóror Helena do Espírito Santo (1649) trabalha com uma cópia, não emite opinião sobre este assunto e apenas relata a visão. Frei Antônio de Almada (1694), todavia, opta 
por transcrever, no capítulo 39 da sua obra, um documento que foi lido no Coro do referido Convento pelo confessor ${ }^{15}$ de Mariana do Rosário:

[...] Escrevo porém a narração deste sucesso sujeita aos limites da doutrina que a Santa Madre Igreja, e sagrada Teologia nos ensinam, e de tal sorte digo o referido, que nem o dou por revelação de Deus, nem pelo contrário. Se Deus foi, ou não foi o autor, ele o descobrirá, se for servido, e em quanto nestas matérias não mostra o Senhor outra clareza, o que havemos de entender é que este caso só merece crédito de história humana, porque a salvação só a dá Deus a quem a procura merecer com muitas virtudes, e com a observância de seus santíssimos preceitos, mediante a divina graça.

[...] Assim se estas Religiosas querem alcançar a ventura que em nome do Senhor se lhes prometeu, saibam que na mão de cada uma está serlhe o recado presente verdadeiro, ou falso, porque se alguma se descuidar de suas obrigações, e faltar ao que deve ao seu estado, chegando a culpa mortal, por esta perde o direito que tem para o Reino de Cristo, que é a salvação, e quem quiser se cumpra em sua alma a verdade desta promessa, deve ser em suas obrigações observante, em sua consciência limpa, em seu espirito devota, em sua alma pura (DECLARAÇÃO e advertências que se deve fazer sobre este sucesso apud ALMADA, 1694, p. 307).

É evidente que, sobre este assunto, Frei Antônio de Almada teria que considerar as limitações e problemas que a declaração da religiosa poderia causar aos seus leitores. As palavras do confessor deixavam claro que poderia existir uma intencionalidade divina ao usar Mariana enquanto intermediária junto às demais freiras para que elas buscassem a reflexão sobre a salvação e seguissem o caminho considerado como correto. Ele, também, informa que caberia somente a Deus julgar a veracidade dessa 'história humana'. Todas as religiosas deveriam seguir o caminho da retidão e não ficar fiadas na promessa declarada por Mariana.

${ }_{15}$ Não foi possível identificar o seu confessor. Aliás, na maioria das obras exemplares, com exceção daquelas escritas pelos próprios confessores, estes aparecem de forma anônima. 


\section{CONSIDERAÇÕES FINAIS}

Será que a obra de Frei Antônio de Almada seria impressa se o autor não apresentasse a reflexão do confessor de Mariana? Alguns indícios esclarecem essa questão a partir dos pareceres dos censores, todos favoráveis à publicação da obra. Frei Tomé da Conceição, carmelita e qualificador do Santo Ofício, informa que o autor, por meio de sua narrativa acerca das diversas visões e 'conversas' sobrenaturais de Mariana do Rosário, deixou claro que ele não teve a intenção de propiciar a criação de uma santa, mas de evidenciar sua exemplaridade para outras pessoas, "[...] e que tudo o que neste livro diz, o refere só dentro dos limites da história humana, por ser capaz de a quem ler poder excitar ao amor de Deus, e das virtudes." Além disso, cita a passagem (Cap. 39, §. 4) sobre a possível salvação coletiva das religiosas, do convento, no Juízo Final: "[...] referindo uma ponderável visão, que essa serva de Deus disse ter". Neste ponto, afirma que o autor "escreveu este livro como teólogo especulativo e místico" (Frei Tomé da Conceição apud ALMADA, 1694, s. n.). Tanto o autor quanto o qualificador do Santo Ofício explicitaram que a narrativa tratava-se de uma história humana que poderia servir de exemplo aos seus leitores. Se levarmos em consideração a hipótese de que Mariana do Rosário escreveu a sua autobiografia, ou ainda por meio da análise da obra transcrita e finalizada por Sóror Helena do Espírito Santo (1649), compreendemos que esses manuscritos, possivelmente, não saíram dos limites do Convento de Salvador de Évora, logo, não passariam pelo crivo dos censores. Para que ocorresse a impressão dessa história era necessária sua adaptação crítica, realizada por um 'sábio' religioso, encarregado de dosar os possíveis limites dogmáticos do escrito.

Ao final deste artigo, precisamos refletir sobre o caráter exemplar das principais obras que circularam nos ambientes claustrais femininos. Como literatura dominante para o público religioso - para além dos desníveis apresentados nas práticas de escritas e de leituras realizadas pelas religiosas -, é necessário considerar a função educativa que as vidas exemplares 
apresentaram. O mundo masculino religioso formado por confessores e censores buscava controlar os ambientes conventuais por meio das 'folhas' que geravam 'frutos', as vidas exemplares. Ressaltamos que este domínio escapava ao controle desses religiosos quando pensamos nas possíveis decodificações e interpretações das leituras por parte das freiras e na diversidade de níveis desta prática, no interior dos claustros. Além disso, é necessário considerar outros gêneros e até a escrita de vidas exemplares que permaneceram manuscritas, no interior dos claustros, e escaparam ao controle da Igreja Católica.

\section{REFERÊNCIAS}

ALGRANTI, Leila Mezan. Livros de devoção, atos de censura: ensaios de história do livro e da leitura na América Portuguesa (1750-1821). São Paulo: Hucitec-Fapesp, 2004.

ALMADA, Fr. Antônio de. Desposorios do Espirito, celebrados entre o divino Amate, e sua amada Esposa a venerável Madre Soror Marianna do Rosário, religiosa do veo branco no Convento do Salvador da cidade de Évora. Lisboa: Oficina de Manoel Lopes Ferreira, 1694.

ANDRADE, Maria Filomena Pimentel de Carvalho. In oboedientia sine proprio. A ordem de Santa Clara em Portugal (sécs. XIII-XIV). 2011. Tese (Doutorado em História) - Universidade Nova de Lisboa, Lisboa, 2011.

BELLINI, Lígia. Cultura escrita, oralidade e gênero em conventos portugueses (séculos XVII e XVIII). Tempo, UFF, Niterói, v. 15, n. 29, p. 211-233, dez. 2010.

BELLINI, Lígia; PACHECO, Moreno Laborda. Experiência e ideais de vida religiosa em mosteiros portugueses clarianos, nos séculos XVII e XVIII.

Revista de História, São Paulo, n. 160, p. 147-167, 2009.

BELO, Filomena. Rellação da vida e morte da serva de Deos a venerável Madre Elenna da Crus por Sóror Maria do Céu. Lisboa: Quimera, 1993.

BLUTEAU, Rafhael. Vocabulário portuguez e latino. v. 3. Coimbra:

Collegio das Artes da Companhia de Jesus, 1728. 
BREVE relação da vida e morte prodigiosa da Madre Maria Joanna. Lisboa: Oficina de Manoel Coelho Amado, 1754.

BURKE, Peter. A invenção da biografia e o individualismo renascentista. Estudos históricos, Rio de Janeiro, n. 19, p. 83-97, 1997.

CARVALHO, José Adriano de Freitas. Do recomendado ao lido. Direcção espiritual e prática de leitura entre franciscanas e clarissas em Portugal no século XVII. Via Spiritus, Universidade do Porto, Porto, v. 4, p. 7-56, 1997.

CASTILLO GÓMEZ, Antonio. Una historia social de la escritura en los siglos de oro. Toledo: Ediciones Akal, 2006

CASTILlO GÓMEZ, Antonio (Org.). Historia de la cultura escrita. Del Próximo Oriente Antiguo a la sociedad informatizada. Espanha: Ediciones Trea, 2001.

CERTEAU, Michel de. A invenção do cotidiano: artes de fazer. Petrópolis: Vozes, 1996.

CHARTIER, Roger. A mão do autor e a mente do editor. São Paulo: UNESP, 2014.

CHARTIER, Roger. A ordem dos livros. Lisboa: Vega, 1997.

CONCÍlIO de Trento. Decreto da escolha dos livros e convite geral através de Salvo Conduto. Sessão XVIII, 1562. Disponível em: http://agnusdei.5Owebs.com/trento23.htm. Acesso em: 28 fev. 2018.

CONSTITUIÇÕES Gerais. Para todas as freiras, e religiosas sujeitas à obediência da Ordem de N. P. S. Francisco, nesta família Cismontana. Lisboa: Oficina de Miguel Deslandes, 1693 .

ESPÍRITO SANTO, Helena. Vida e morte de Soror Marianna do Rosário Religiosa professa filha da Me. Sta Clara que viveo e morreo com opinião de Sancta em o Religioso Convento de Salvador da cidade de Évora. Manuscrito, 1649. (Acervo Biblioteca Pública de Évora - CV 1-20).

FARIA, Francisco Leite (Org.). Santa Clara e as clarissas em Portugal. Lisboa: Biblioteca Nacional de Portugal, 1994.

FEITLER, Bruno. A delegação de poderes inquisitoriais: o exemplo de Goa através da documentação da Biblioteca Nacional do Rio de Janeiro. Tempo, UFF, Niterói, v. 12, n. 24, p. 127-148, 2008.

GALVÃO, Ana Maria. História das culturas do escrito: tendências e 
possibilidade de pesquisa. In: MARINHO, Marildes; CARVALHO, Gilcinei Teodoro (Org.). Cultura escrita e letramento. Belo Horizonte: Editora UFMG, 2010. p. 65-95.

GOMEZ, Antonio Castillo. Historia de la cultura escrita: ideas para el debate. Revista brasileira de história da educação, Universidade Estadual de Maringá, Maringá, v. 3, n. 1 [5], p. 93-124, jan./jun. 2003.

GONZÁLEZ DE LA PEÑA, María del Val (Org.). Mujer y cultura escrita. Del mito al siglo XXI. Espanha: Ediciones Trea, 2005.

GRAÑA CID, Maria del Mar. Leer con el alma y escribir con el cuerpo?

Reflexiones sobre mujeres y cultura escrita. In: GOMEZ, Antonio Castillo (Org.). Historia de la cultura escrita. Del Próximo Oriente Antiguo a la sociedad informatizada. Gijon, Asturias: Ediciones Trea, 2001. p. 385-450.

HATHERLY, Ana. A preciosa de sóror Maria do Céu. Lisboa: Instituto Nacional de Investigação Científica, 1990.

HUFTON, Olwen. Mulheres, trabalho e família. In: DUBY, George; PERROT, Michele (Org.). História das mulheres: do Renascimento à Idade Moderna. Porto: Afrontamento, 1991. p. 23-69.

LAGE, Ana Cristina Pereira. Mulheres de véu preto: letramento religioso das irmãs clarissas na América Portuguesa. História: Questões e Debates, UFPR, Curitiba, v. 6o, n. 1, p. 107-131, jan./jun. 2014.

LAGE, Ana Cristina Pereira. Petites Marthes: educação para meninas pobres do Colégio Nossa Senhora de Sion de Campanha, MG. In: JACOMELI, Mara; SANFELICE, José Luis (Org.). Histórias de instituições escolares: teoria e prática. Bragança Paulista, SP: Margem da Palavra, 2016. p. 97-118.

LAGE, Ana Cristina Pereira. Práticas de escrita e de leitura no Convento de Santa Clara do Desterro da Bahia (séculos XVII e XVIII). Notandum, USP, São Paulo, v. 21, p. 78-98, 2018.

LEBRUN, François. Devoções comunitárias e piedade pessoal. In: ARIÈS, Philippe; CHARTIER, Roger (Org.). História da vida privada. v. 3. São Paulo: Companhia das Letras, 1991. p. 71-111.

MARIN, Miguel Angelo. A perfeita religiosa: obra igualmente útil a todas as pessoas que aspirão a perfeição. Lisboa: Oficina de Simão Thaddeo Ferreira, 1789.

MENINO JESUS, Isabel do. Vida da venerável madre Isabel do Menino 
Jesus. Lisboa: Oficina de José da Costa Coimbra, 1757.

MILHEIRO, Dalila Maria Teixeira. Dimensões do feminino na Fiel e Verdadeyra Relação que dá dos sucessos de sua vida a criatura mais ingrata a seu Creador por obediência de seus Padres Espirituaes e novamente tornada a escrever por hum sucesso na era de 1685 annos de Clara do Santissimo Sacramento. 2004. $183 \mathrm{f}$. Dissertação (Mestrado em Estudos sobre as Mulheres) - Universidade Aberta, Lisboa, 2004.

MORUJÃO, Isabel. Morrer ao pé da letra: relatos de morte na clausura feminina portuguesa. Via Spiritus, Universidade do Porto, Porto, v. 15, p. 163-194, 2008.

MORUJÃO, Isabel. Contributo para uma bibliografia cronológica da literatura monástica feminina portuguesa dos séculos XVII e XVIII (impressos). Lisboa: Centro de Estudos de História Religiosa - Universidade Católica Portuguesa, 1995.

MORUJÃO, Isabel. Por trás das grades: poesia conventual feminina em Portugal (séculos XVI-XVIII). Lisboa: Imprensa Nacional-Casa da Moeda, 2013.

PACHECO, Moreno Laborda. “A magoa de ver hir esquecendo...”. Escrita conventual feminina no Portugal do século XVII. 2013. Tese (Doutorado em História) - Universidade Federal da Bahia/UFBA. Salvador, 2013.

PAULO, Maria Manuela. Aves ilustradas (excertos). In: MAGALHÃES, Isabel Allegro (Org.). História e antologia da literatura portuguesa - Século XVIII. Literatura de conventos. Autoria Feminina. Lisboa: Fundação Calouste Gulbenkian, 2005. p. 15-17.

PURIFICAÇÃO, Marianna da. Informações da vida da madre Marianna da Purificação e sua vida escrita por ella mesma. Manuscrito, 1694. (Acervo Biblioteca Pública de Évora - cod.CV 1-20)

REGRA do glorioso patriarca São Bento. C. 530. Disponível em: http://www.ricardocosta.com/traducoes/textos/regra-de-sao-bento-c-530. Acesso em: 12 mar. 2018.

VIEIRA, Celia Sousa. Biografia e vida devota no século XVIII: a Vida Maravilhosa de Soror Clara Gertrudes do Sacramento de Frei Afonso dos Prazeres. 1996. 245 f. Dissertação (Mestrado em História da Cultura Portuguesa) - Universidade do Porto, Porto, 1996. 
ANA CRISTINA PEREIRA LAGE é professora dos cursos de Licenciatura em História e Mestrado Profissional Interdisciplinar em Ciências Humanas (UFVJM). Possui Graduação em História (UFMG). Mestrado em Educação (Unicamp). Doutorado em Educação (UFMG). Pós-Doutorado em Educação (UEM); supervisão Dra. Terezinha Oliveira (UEM); Bolsista Capes.

E-mail: anaplage@uol.com.br

(1) http://orcid.org/0000-0003-2716-6847

TEREZINHA OLIVEIRA é professora Titular da Universidade Estadual de Maringá junto ao Departamento de Fundamentos da Educação e ao Programa de Pós-Graduação em Educação. Diretora da Editora da Universidade Estadual de Maringá (Eduem), desde 2014. Possui graduação em História pela Universidade Estadual Paulista Júlio de Mesquita Filho (1986), mestrado em Ciências Sociais pela Universidade Federal de São Carlos (1991) e doutorado em História pela Universidade Estadual Paulista Júlio de Mesquita Filho (1997). Realizou, em 2004, estágio de Pós-Doutorado em História e Filosofia da Educação na Faculdade de Educação da USP.

E-mail: teleoliv@gmail.com

(i) http://orcid.org/0000-0001-5349-1059

Recebido em: 27 de março de 2018

Aprovado em: 10 de abril de 2019 